\title{
INFLUÊNCIA DO TIPO DE AMIDO NA TEXTURA E DERRETIMENTO DE REQUEIJÃO CULINÁRIO
}

\section{Gabriela V. Shie*, Caroline B. Karaziack, Ana P. Barth, Laís R. Fontanesi, Walkíria H. Viotto}

\section{Resumo}

Atualmente, o requeijão é o queijo mais produzido do Brasil. Isso se deve tanto ao seu consumo direto quanto seu uso como ingrediente culinário. A adição de amido pode influenciar positivamente na funcionalidade e textura do requeijão. O objetivo deste trabalho foi estudar o efeito de diferentes tipos de amido (milho, mandioca e batata) na composição química, textura e derretimento de requeijão cremoso. Análises de $\mathrm{pH}$, composição, perfil de textura e derretimento foram realizadas para todos os requeijões. $O$ amido conseguiu aumentar a firmeza e a adesividade do requeijão, melhorando sua textura, além de diminuir seu derretimento, assemelhando-se a um requeijão culinário. $O$ requeijão com amido de milho foi o que se mostrou mais firme e apresentou menor derretimento.

Palavras-chave: Queijos fundidos, estrutura, funcionalidade.

\section{Introdução}

A incorporação de amido ao requeijão pode ajudar a controlar a textura e o derretimento do requeijão, devido a sua capacidade de absorção de água quando submetido ao aquecimento, reduzindo a mobilidade de água do sistema'. Amidos são constituídos de cadeias de amilose e amilopectina. Variações na proporção dessas cadeias resultam em diferenças nas propriedades do amido, bem como o tamanho dos grânulos de cada variedade. Além disso, o uso do amido reduz os custos de produção.

O objetivo deste trabalho foi estudar o efeito de diferentes tipos de amido (milho, mandioca e batata) na composição química, textura e derretimento de requeijão cremoso.

\section{Resultados e Discussão}

Todos os teores de umidade estão dentro do permitido para requeijão cremoso (máx 65\%) e GBS maior que $55 \%$, estando de acordo com a legislação brasileira. Foi adicionada às formulações uma quantidade de $3 \%$ dos respectivos amidos, com exceção do controle (Tabela 1).

A presença do amido nos requeijões reduziu o seu derretimento quando aquecido, sendo o de mandioca o que apresentou o menor derretimento ao contrário do controle (sem amido) que não foi capaz de apresentar tal funcionalidade (Tabela 1).

Tabela1. Caracterização físico-química dos requeijões e derretimento

\begin{tabular}{ccccc}
\hline & Controle & Batata & Mandioca & Milho \\
\hline Umidade & $60,71 \pm 0,14$ & $60,93 \pm 0,47$ & $61,45 \pm 0,37$ & $60,70 \pm 0,20$ \\
Gordura & $26,69 \pm 0,62$ & $24,57 \pm 0,21$ & $24,48 \pm 0,62$ & $24,29 \pm 0,42$ \\
Proteína & $10,90 \pm 0,19$ & $10,79 \pm 0,06$ & $10,56 \pm 0,15$ & $10,68 \pm 0,06$ \\
pH & $6,09 \pm 0,02$ & $5,61 \pm 0,01$ & $5,65 \pm 0,02$ & $5,63 \pm 0,03$ \\
Cinzas & $1,33 \pm 0,01$ & $1,24 \pm 0,05$ & $1,21 \pm 0,02$ & $1,28 \pm 0,01$ \\
GBS* & 67,93 & 62,89 & 63,51 & 61,79 \\
$\begin{array}{c}\text { Derretimento } \\
\text { (mm) }\end{array}$ & $200 \pm 0,0$ & $65 \pm 0,75$ & $27 \pm 0,51$ & $34 \pm 0,47$ \\
\hline
\end{tabular}

*Gordura em base seca
A presença de amido (3\%) influenciou a textura do requeijão. O tipo de amido afetou os parâmetros de adesividade e firmeza, enquanto que a elasticidade e a coesividade não sofreram mudanças significativas pela adição do amido, qualquer que fosse a sua origem botânica. O requeijão adicionado de amido de milho foi o que apresentou os maiores valores de firmeza, seguido da mandioca e da batata em adesividade (Figura 1).

Textura TPA

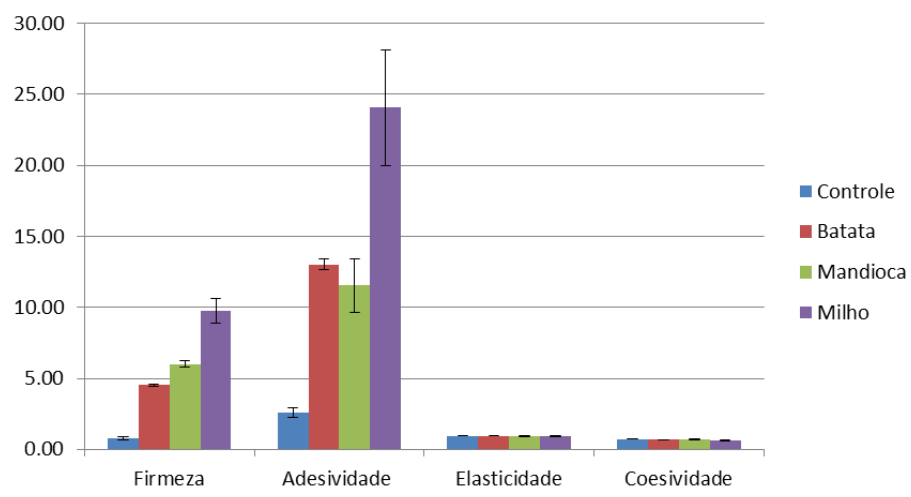

Figura 1. Parâmetros de textura para os requeijões cremosos controle e com adição de diferentes tipos de amidos.

\section{Conclusões}

$A$ adição de amido influenciou nas propriedades funcionais do requeijão cremoso como textura e derretimento. As alterações variaram de acordo com o tipo de amido, em que o produto apresentou características semelhantes às de um requeijão culinário. $\mathrm{O}$ amido de milho foi o que proporcionou maior firmeza e menor derretimento.

\section{Agradecimentos}

Agradeço ao SAE/UNICAMP pela concessão da bolsa.

${ }^{1}$ NORONHA, N.; DUGGAN, E.; ZIEGLER, G.R.; O'RIORDAN, E.D.; O'SULLIVAN, M Inclusion of starch in imitation cheese: Its influence on water mobility and cheese functionality. Food Hydrocolloids, v.22, p.1612-1621, 2008. 